\title{
Characterizing idiopathic pulmonary fibrosis patients using US Medicare- advantage health plan claims data
}

\author{
Kathleen Mortimer ${ }^{1}$, Nadine Hartmann², Christine Chan ${ }^{1}$, Heather Norman ${ }^{1}$, Laura Wallace ${ }^{3}$ and Cheryl Enger ${ }^{4^{*}}$
}

\begin{abstract}
Background: Idiopathic pulmonary fibrosis (IPF) is a rare life-threating interstitial lung disease (ILD). This study characterizes demographics, health care utilization, and comorbidities among elderly IPF patients and estimates prevalence and incidence rates for selected outcomes.

Methods: Cohort study using a large US health insurance database (Optum's Medicare Advantage plan). Inclusion criteria: $\geq 1$ diagnosis code for IPF (2008 - 2014), age $\geq 65$ years, no diagnosis of IPF or other ILD in prior 12 months. Demographics, health care utilization, comorbidities and incidence rates for various outcomes were estimated. Follow-up continued until the earliest of: health plan disenrollment, death, a claim for another known cause of ILD, or end of the study period.

Results: 4,716 patients were eligible; $53.4 \%$ had IPF diagnostic testing. Median age was 77.5 years, 50.3\% were male, median follow-up time was 0.8 years. Incidence rates ranged from 1.0/1,000 person-years (lung transplantation) to 374.3/1,000 person-years (arterial hypertension). Baseline characteristics and incidence rates were similar for cohorts of patients with and without IPF diagnostic testing.
\end{abstract}

Conclusions: Elderly IPF patients experience a variety of comorbidities before and after IPF diagnosis. Therapies for IPF and for the associated comorbidities may reduce morbidity and associated health care utilization of these patients.

Keywords: Idiopathic pulmonary fibrosis, Claims data, Elderly, Medicare

\section{Background}

Idiopathic pulmonary fibrosis (IPF) is a rare interstitial lung disease (ILD) which is progressive and life-threatening. It generally occurs in patients over the age of 50 years. The diagnosis is challenging as IPF shares symptoms with many other kinds of lung disease, but improvements in diagnosis have been made $[1,2]$. Diagnostic criteria include the presence of a specific radiologic pattern of usual interstitial pneumonia (UIP) on HRCT, or specific combinations of radiologic and histopathologic patterns in patients who have undergone a surgical lung biopsy $[1,3]$. Nintedanib and pirfenidone were both approved for use in the United States (US) by the Food and Drug Administration (FDA) in October

\footnotetext{
* Correspondence: cheryl.enger@optum.com

${ }^{4}$ Optum Epidemiology, 315 E. Eisenhower Parkway, Suite 305, Ann Arbor, MI 48108, USA

Full list of author information is available at the end of the article
}

2014. These were the first pharmacological treatments shown to be efficacious in patients with IPF, leading to slower disease progression $[4,5]$. The objective of this study was to characterize the IPF population aged 65 years and above prior to the marketing of pharmaceutical treatments for IPF to gain a better understanding of the characteristics and disease outcomes.

\section{Methods \\ Data Source}

This non-interventional cohort study was based on a proprietary research database containing eligibility, pharmacy claims, and medical claims data from a Medicare Advantage and Part D plan (MAPD) managed by Optum. Medical and pharmacy claims data are available starting in 2006 for approximately 4.2 million members. Medicare Advantage plans are offered by private 
companies, such as the health insurer associated with Optum, and approved by Medicare.

Medical and pharmacy information, including inpatient and outpatient procedures and diagnoses, is available for Medicare enrollees with medical and pharmacy coverage. Pharmacy claims contain sufficient information to trace patients' pharmacy expenditures through the multiple phases of the Part D plans, although information on medications administered during inpatient stays is not captured. All data access conforms to applicable Health Insurance Portability and Accountability Act policies.

To identify possible out-of-hospital deaths, claims data were linked to the Social Security Administration (SSA) Death Master File (DMF), a compilation of mortality information derived from the US SSA payment records. The DMF currently contains over 94 million records. Information on cause of death is not included.

\section{Cohort Identification}

Patients with at least one medical claim with a diagnosis code of IPF and aged 65 years or older between 01 January 2008 and 30 September 2014 were identified. The ICD-9 code for IPF was 516.3 prior to October 2011, and changed to 516.31 in October 2011. Patients were required to have complete medical coverage and pharmacy benefits and at least 12 months of continuous health plan enrollment prior to the IPF claim date (baseline period).

The cohort entry date (index date) was set as the date of the first medical claim with a diagnosis of IPF within the study period. Only incident cases, defined as IPF patients without IPF claims in the baseline period were eligible for this study. Patients with other known causes of ILD such as connective tissue disease, hypersensitivity pneumonitis and others during baseline were excluded (Additional file 1, [3]). Patients with claims for IPF diagnostic testing (high-resolution computed tomography (HRCT) of the thorax or surgical lung biopsy (SLB) during baseline) were identified for a subgroup analysis (referred to as the IPF diagnostic testing subgroup). This was a stricter case definition done to identify a subgroup who would more definitively be considered to have IPF, to assess how the case definition may influence the results. The number of patients with IPF diagnostic testing in the first 30 days after diagnosis was also evaluated.

Since IPF shares symptoms with many other lung diseases, it is possible for a diagnosis of IPF to be made, then later modified to an alternate ILD diagnosis. These patients are included in the primary analysis so as not to use future events to classify patients at baseline). For exploratory purposes, however, a sensitivity analysis excluding patients who had at least one claim during follow-up for one of the ILD conditions (listed in
Additional file 1) was done to estimate the impact of these potentially misdiagnosed members of the cohort on the baseline characteristic distributions and outcomes.

\section{Baseline characteristics}

Baseline characteristics include age at cohort entry, sex, geographic area, race, length of health plan membership prior to cohort entry, cohort entry year, medication dispensings of: oral corticosteroids, $\mathrm{N}$-acetyl cysteine (NAC), azathioprine and cyclophosphamide, open lung biopsies, oxygen therapy, medication for gastroesophageal reflux disease (GERD) therapy (e.g., H2 receptor blockers, proton pump inhibitors), anticoagulation (e.g., vitamin $\mathrm{K}$ antagonists, heparin, novel oral anticoagulants and antiplatelet therapy), dispensings of drugs that may induce pulmonary fibrosis (amiodarone, bleomycin, nitrofurantoin, methotrexate, gold salts), Epstein-Barr virus (EBV), hepatitis $\mathrm{C}$, and broncho-alveolar lavage. Conditions defined in the list of primary and secondary outcomes below were also included in the list of baseline conditions, as were measures of health care utilization (HCRU) such as number of inpatient and outpatient visits and associated costs.

\section{Outcomes}

Primary outcomes include acute respiratory worsening of unknown cause (ARWUC) [6], pulmonary hypertension $(\mathrm{PH})$ [7], pulmonary arterial hypertension $(\mathrm{PAH})$ [7], lung transplantation, lung cancer [8, 9], acute myocardial infarction (AMI), and all-cause mortality. Secondary outcomes include gastrointestinal (GI) perforation [10], chronic renal failure/insufficiency [11, 12], hemorrhagic diathesis or coagulopathy, venous thrombosis [13], pulmonary embolism [7], stroke, cardiac arrhythmia [13], congestive heart failure [14], ischemic heart disease [15, 16], arterial hypertension [17, 18], neutropenia [19], pneumonia [20], sepsis [21], chronic obstructive pulmonary disease (COPD) [22], GERD [23, 24], type 2 diabetes mellitus [25], obstructive sleep apnea, bronchitis, upper respiratory tract infection, pulmonary rehabilitation, acute coronary syndrome, angina pectoris, bleeding (including major upper and lower GI bleeding, hemorrhage of the rectum or anus, blood in stool, epistaxis, hemorrhoids, hemorrhoids with bleeding, intracranial hemorrhage), acute pancreatitis, hepatic failure, acute renal failure and two definitions of depression, including major depressive disorder (MDD) only, and MMD and other types of depression.

When available, algorithms that have been validated in administrative databases were used to define outcomes of interest. Otherwise, outcome definitions were 
determined with clinical input and searches of medical claims coding systems.

Follow-up time for each cohort member extended from the day after the index date until the earliest of disenrollment from the health plan, death, occurrence of baseline exclusion criterion during follow-up, or the end of the study period. For each outcome, patients were censored for any second occurrences of that outcome, but remained eligible for a different outcome.

\section{Statistical Methods}

Mean, standard deviation (SD), median and interquartile ranges (IQR) were calculated for continuous variables and absolute and relative frequencies were calculated for categorical variables.

For the baseline characteristics, relative frequencies (prevalences) were calculated by dividing the number of patients in the cohort with the condition during baseline by the total number of patients in the cohort. Incidence rates (IRs) were calculated by dividing the number of patients with the outcome by the sum of all observation time-to-event or censoring for all patients within each cohort. IRs are presented per 1,000 person-years (pys) with 95\% confidence intervals (CIs). They are shown only for the patients who did not have evidence of the condition during baseline. Length of follow-up (mean, $\mathrm{SD}$, median, interquartile range (IQR)) was summarized by reason for censoring.

All analyses were conducted using SAS 9.4.

\section{Results}

A total of 4,716 incident cases of IPF were identified. The median age of these patients was 77.5 years (IQR: $72.0,82.0), 50.3 \%$ were male, and the majority (74.1\%) were white. Approximately half $(\mathrm{n}=2,223,47.1 \%)$ entered the cohort before October 2011, and 2,493 (53.9\%) patients entered the cohort after the change in ICD-9 coding in October 2011. The most commonly observed pre-specified baseline medications were GERD therapies (34.9\%) and oral corticosteroids (33.4\%) (Table 1). Within the IPF cohort, $53.4 \%(\mathrm{n}=2,518)$ had IPF diagnostic testing, of which $97.7 \%$ of the patients had claims for HRCT testing only, $0.3 \%$ had only surgical lung biopsy claims, and $2.0 \%$ had claims for both HRCT and surgical lung biopsy (data not shown). When the time period for possible diagnostic testing was extended beyond baseline to include the 30 days after the cohort entry date, an additional 437 patients were identified with IPF diagnostic testing (data not shown).

The baseline characteristics of the IPF cohort and subgroup with IPF diagnostic testing during baseline were similar, overall and within stratum of cohort entry time based on changes in ICD-9 coding (i.e., cohort entry before October 2011 vs during or after October 2011).
Due to the similarity of characteristics, all results are reported without stratification by cohort entry time.

Baseline HCRU metrics are summarized in Table 2. Half of the IPF cohort (50.8\%) was hospitalized and $82.9 \%$ had dispensings for at least 3 unique medications. The median number of physician visits was 12.0 (IQR: 8.0-19.0). The median total cost was $\$ 11,865$ (IQR: $2,465-25,113)$. Nearly half of the costs were from facility charges, which is consistent with the observed proportion of patients with inpatient hospitalizations.

The mean length of time from cohort entry until censoring was 1.3 years (SD 1.4, median 0.8) (Table 3). The most common reason for censoring (other than the end of the study period) was the end of health plan enrollment (27.3\% and $26.3 \%$, for IPF cohort and IPF diagnostic testing subgroup). The smallest proportion of patients in each cohort was censored because one of the baseline exclusion criteria (e.g., other known causes of ILD) was observed during follow-up (17.1\% and 19.1\%, respectively.)

The baseline prevalence of the primary and secondary conditions are presented in Table 4. With the exception of lung cancer $(16.1 \%)$, the prevalence was low for the primary conditions, ranging from $0.2 \%$ for $\mathrm{PAH}$ and lung transplantation to $4.6 \%$ for $\mathrm{PH}$ in the IPF cohort. Among the secondary conditions, the prevalence ranged from $\leq 1 \%$ for GI perforation, neutropenia, hemorrhoids with bleeding, intracranial hemorrhage, acute pancreatitis, and hepatic failure to the highest prevalence estimate of $76.3 \%$ for arterial hypertension. The results were similar for the IPF diagnostic testing subgroup.

The incidence of the outcomes for the IPF cohort and IPF diagnostic testing subgroup are summarized in Table 5. In the IPF cohort, the IRs of the primary outcomes during follow-up ranged from 1.0/1,000 pys for lung transplantation to $180.4 / 1,000$ pys for all-cause mortality. IRs of the secondary outcomes ranged from $3.7 / 1,000$ pys for hepatic failure to $374.3 / 1,000$ pys for arterial hypertension, respectively. Overall, IRs of most of the primary and secondary outcomes were slightly lower in the IPF cohort relative to the IPF diagnostic testing subgroup.

The results were not substantially affected when patients who had claims during follow-up for other known causes of ILD (i.e., claims suggesting they were misdiagnosed as IPF at cohort entry) were excluded $(\mathrm{n}=808,17 \%$, data not shown). One notable exception was that this subset of patients had a higher all-cause mortality rate (201.7/1,000 pys).

\section{Discussion}

The results of this study suggest that IPF patients aged 65 years and above have a high morbidity and mortality. It included a broad range of comorbidities and outcomes, some of which have only been rarely or not been 
Table 1 Baseline characteristics of IPF Patients

\begin{tabular}{|c|c|c|c|c|}
\hline \multirow{2}{*}{ Age (continuous, years } & \multicolumn{2}{|c|}{$\begin{array}{l}\text { IPF Cohort } \\
(N=4,716)\end{array}$} & \multicolumn{2}{|c|}{$\begin{array}{l}\text { IPF Diagnostic Testing Subgroup } \\
(N=2,518)\end{array}$} \\
\hline & & & & \\
\hline Median, IQR & 77.5 & $72.0-82.0$ & 77.0 & $71.0-81.0$ \\
\hline Mean, SD & 76.8 & 5.9 & 76.3 & 5.8 \\
\hline \multicolumn{5}{|c|}{ Length of Health Plan Membership Prior to Cohort Entry (continuous, months) } \\
\hline Median, IQR & 34.3 & $21.5-58.6$ & 34.7 & $21.6-59.1$ \\
\hline \multirow[t]{2}{*}{ Mean, SD } & 47.6 & 37.9 & 48.1 & 38.4 \\
\hline & N & $\%$ & N & $\%$ \\
\hline \multicolumn{5}{|l|}{ Age (years) } \\
\hline $65-74$ & 1,683 & 35.7 & 981 & 39.0 \\
\hline $75-84$ & 2,633 & 55.8 & 1,366 & 54.2 \\
\hline $85+^{a}$ & 400 & 8.5 & 171 & 6.8 \\
\hline \multicolumn{5}{|l|}{ Sex } \\
\hline Male & 2,374 & 50.3 & 1,319 & 52.4 \\
\hline Female & 2,342 & 49.7 & 1,199 & 47.6 \\
\hline \multicolumn{5}{|l|}{ Geographic Area } \\
\hline Northeast & 821 & 17.4 & 467 & 18.5 \\
\hline Midwest & 1,665 & 35.3 & 909 & 36.1 \\
\hline South & 1,776 & 37.7 & 911 & 36.2 \\
\hline West & 454 & 9.6 & 231 & 9.2 \\
\hline \multicolumn{5}{|l|}{ Race } \\
\hline White & 3,496 & 74.1 & 1,899 & 75.4 \\
\hline African American & 489 & 10.4 & 234 & 9.3 \\
\hline Hispanic/Latino & 302 & 6.4 & 170 & 6.8 \\
\hline Asian & 113 & 2.4 & 49 & 1.9 \\
\hline Other & 316 & 6.7 & 166 & 6.6 \\
\hline Cohort Entry Period & $\mathrm{N}$ & $\%$ & N & $\%$ \\
\hline $2008-2009$ & 970 & 20.6 & 525 & 20.8 \\
\hline $2010-2011$ & 1,401 & 29.7 & 731 & 29.0 \\
\hline $2012-2014$ & 2,345 & 49.7 & 1,262 & 50.1 \\
\hline
\end{tabular}

Patients with at Least One

Diagnosis, Procedure, or

Dispensing for each of the

Following During the 12-Month Baseline Period:

\begin{tabular}{|c|c|c|c|c|}
\hline Any Corticosteroid & 1,577 & 33.4 & 952 & 37.8 \\
\hline NAC & 40 & 0.8 & 24 & 1.0 \\
\hline Azathioprine & 27 & 0.6 & 15 & 0.6 \\
\hline Cyclophosphamide & 13 & 0.3 & 11 & 0.4 \\
\hline Open Lung Biopsies & 22 & 0.5 & 22 & 0.9 \\
\hline Oxygen Therapy & 1,093 & 23.2 & 654 & 26.0 \\
\hline GERD Therapy & 1,645 & 34.9 & 912 & 36.2 \\
\hline Anticoagulation/Antiplatelet Therapy & 1,346 & 28.5 & 781 & 31.0 \\
\hline Amiodarone & 172 & 3.6 & 107 & 4.2 \\
\hline Bleomycin & 2 & 0.0 & 2 & 0.1 \\
\hline
\end{tabular}


Table 1 Baseline characteristics of IPF Patients (Continued)

\begin{tabular}{lllll}
\hline & IPF Cohort & & \multicolumn{2}{l}{ IPF Diagnostic Testing Subgroup } \\
& $(N=4,716)$ & & 95 & 3.8 \\
\hline Nitrofurantoin & 207 & 4.4 & 8 & 0.3 \\
Methotrexate & 15 & 0.3 & 0 & 0.0 \\
Gold Salts & 0 & 0.0 & 7 & 0.3 \\
Epstein-Barr Virus & 9 & 0.2 & 73 & 2.9 \\
Hepatitis C & 105 & 2.2 & 139 & 5.5 \\
Bronchial Lavage & 150 & 3.2 & \\
\hline
\end{tabular}

Optum Research Database - Medicare Advantage Population. Cohort Entry: 01 January 2008 - 30 September 2014

Abbreviations: IPF idiopathic pulmonary fibrosis, NAC N-acetyl cysteine, IQR interquartile range, SD standard deviation, GERD gastroesophageal reflux disease

${ }^{a}$ For privacy reasons, the earliest year of birth in the MAPD is coded as 1927 , so no patients in the cohort entry period prior to 2011 can be coded as age $>=85$. Counts for patients who entered the cohort before October 2011 and whose actual age is $>=85$ are collapsed into the $75-84$ year grouping in this report

yet characterized in IPF populations. In particular, no published studies were found that included the prevalence or incidence of outcomes such as hepatic failure, acute pancreatitis or acute renal failure.

The patients included in this study are from a wide range of providers covered by Medicare, not restricted to major medical facilities, thus also reflecting diagnoses given by providers in general practice. Within the incident IPF cohort of 4,716 patients, over one half of the patients had a procedure for IPF diagnostic testing during baseline, the vast majority of which was HRCT rather than surgical biopsy. Surgical lung biopsy is an invasive diagnostic test; both HRCT and lung biopsy would tend to be performed only in larger medical settings. Although surgical lung biopsy was recommended by the 2011 international guidelines for the

Table 2 Health care utilization among IPF patients during the 12-month baseline period

\begin{tabular}{|c|c|c|c|c|c|c|}
\hline & \multicolumn{3}{|l|}{$\begin{array}{l}\text { IPF Cohort } \\
(N=4,716)\end{array}$} & \multicolumn{3}{|c|}{$\begin{array}{l}\text { IPF Diagnostic Testing Subgroup } \\
(N=2,518)\end{array}$} \\
\hline & $\mathrm{N}$ & \multicolumn{2}{|l|}{$\%$} & $\bar{N}$ & \multicolumn{2}{|l|}{$\%$} \\
\hline No Medication within 12 Months of Cohort Entry & 570 & \multicolumn{2}{|l|}{12.1} & 298 & \multicolumn{2}{|l|}{11.8} \\
\hline One Medication within 12 Months of Cohort Entry & 136 & \multicolumn{2}{|l|}{2.9} & 59 & \multicolumn{2}{|l|}{2.3} \\
\hline Two Medications within 12 Months of Cohort Entry & 100 & \multicolumn{2}{|l|}{2.1} & 46 & \multicolumn{2}{|l|}{1.8} \\
\hline $\begin{array}{l}\text { Three or More Medications within } 12 \text { Months of } \\
\text { Cohort Entry }\end{array}$ & 3,910 & \multicolumn{2}{|l|}{82.9} & 2,115 & \multicolumn{2}{|l|}{84.0} \\
\hline $\begin{array}{l}\text { Any Hospitalization within } 12 \text { Months of Cohort } \\
\text { Entry (yes/no) }\end{array}$ & 2,396 & \multicolumn{2}{|l|}{50.8} & 1,401 & \multicolumn{2}{|l|}{55.6} \\
\hline \multirow[t]{2}{*}{ Critical Care Evaluation and Management } & 722 & \multicolumn{2}{|l|}{15.3} & 447 & \multicolumn{2}{|l|}{17.8} \\
\hline & Mean (SD) & Median & IQR & Mean (SD) & Median & IQR \\
\hline Number of Physician Visits ${ }^{\mathrm{a}}$ & $14.8(10.8)$ & 12.0 & $8.0-19.0$ & $16.2(11.6)$ & 14.0 & $9.0-21.0$ \\
\hline Number of Emergency Department Visits ${ }^{a}$ & $1.4(2.2)$ & 1.0 & $0.0-2.0$ & $1.5(2.4)$ & 1.0 & $0.0-2.0$ \\
\hline Number of Inpatient Stays & $0.9(1.2)$ & 1.0 & $0.0-1.0$ & $1.0(1.3)$ & 1.0 & $0.0-1.0$ \\
\hline Number of Inpatient Days & $7.2(18.0)$ & 1.0 & $0.0-6.0$ & $8.4(19.3)$ & 1.0 & $0.0-8.0$ \\
\hline Number of 3-Digit Diagnosis Codes & $31.6(14.7)$ & 29.0 & $21.0-40.0$ & $34.4(14.9)$ & 32.0 & $23.0-43.0$ \\
\hline Number of Surgical Procedures ${ }^{a}$ & $7.6(7.2)$ & 6.0 & $3.0-10.0$ & $8.4(7.9)$ & 6.0 & $3.0-11.0$ \\
\hline Number of Anesthesia Procedures ${ }^{a}$ & $0.5(0.9)$ & 0.0 & $0.0-1.0$ & $0.5(0.9)$ & 0.0 & $0.0-1.0$ \\
\hline Number of Unique Drugs Dispensed & $10.3(7.4)$ & 10.0 & $5.0-15.0$ & $10.8(7.7)$ & 10.0 & $5.0-16.0$ \\
\hline Medical Costs (\$) & $6,033.9(9,319.3)$ & $3,932.7$ & $2,156.7-6,986.0$ & $6,983.1(9,791.5)$ & $4,479.6$ & $2,684.1-7,864.9$ \\
\hline Facility Costs (\$) & $12,474.9(22,355.4)$ & $4,845.6$ & $864.9-15,263.1$ & $15,086.9(26,551.3)$ & $6,430.2$ & $1,424.9-18,539.2$ \\
\hline Pharmacy Costs (\$) & $2,675.3(5,854.3)$ & $1,350.8$ & $326.7-3,186.2$ & $2,787.4(5,989.5)$ & $1,463.7$ & $355.3-3,238.8$ \\
\hline Total Costs (\$) & $21,184.2(28,913.5)$ & $11,865.2$ & $5,465.4-25,713.4$ & $24,857.5(33,600.8)$ & $13,798.3$ & $6,739.4-30,886.0$ \\
\hline
\end{tabular}

Optum Research Database - Medicare Advantage Population. Cohort Entry: 01 January 2008 - 30 September 2014

Abbreviations: IR incidence rate per 1,000 person-years, IQR interquartile range, SD standard deviation, $C I$ confidence interval, IPF idiopathic pulmonary fibrosis, GERD gastroesophageal reflux disease, Gl gastrointestinal, $M D D$ major depressive disorder

${ }^{a}$ One of each type counted per day 
Table 3 Length of follow-up among IPF patients

\begin{tabular}{|c|c|c|c|c|c|}
\hline \multirow[t]{2}{*}{ Cohorts } & \multicolumn{5}{|c|}{ Length of Follow-Up (in Years) } \\
\hline & $\mathrm{N}$ & $\%$ & Mean (SD) & Median & Interquartile Range \\
\hline IPF Cohort & 4,716 & 100.0 & $1.3(1.4)$ & 0.8 & $0.2-1.8$ \\
\hline \multicolumn{6}{|l|}{ Reason for Censoring: } \\
\hline End of Study Period & 1,537 & 32.6 & $1.8(1.7)$ & 1.3 & $0.5-2.7$ \\
\hline Death & 1,082 & 22.9 & $0.9(1.1)$ & 0.5 & $0.1-1.4$ \\
\hline End of Health Plan Enrollment & 1,289 & 27.3 & $1.2(1.2)$ & 0.9 & $0.3-1.8$ \\
\hline Exclusion Criteria Observed & 808 & 17.1 & $0.8(1.0)$ & 0.4 & $0.1-1.1$ \\
\hline IPF Diagnostic Testing Subgroup & 2,518 & 100.0 & $1.2(1.4)$ & 0.7 & $0.2-1.7$ \\
\hline \multicolumn{6}{|l|}{ Reason for Censoring: } \\
\hline End of Study Period & 793 & 31.5 & $1.8(1.7)$ & 1.2 & $0.5-2.7$ \\
\hline Death & 584 & 23.2 & $0.9(1.1)$ & 0.4 & $0.1-1.2$ \\
\hline End of Health Plan Enrollment & 661 & 26.3 & $1.2(1.2)$ & 0.8 & $0.3-1.8$ \\
\hline Exclusion Criteria Observed & 480 & 19.1 & $0.7(0.9)$ & 0.3 & $0.1-1.0$ \\
\hline
\end{tabular}

Optum Research Database - Medicare Advantage Population. Cohort Entry: 01 January 2008 - 30 September 2014

Abbreviations: IPF idiopathic pulmonary fibrosis, SD standard deviation

confirmation of the IPF diagnosis in patients who have a possible or probable UIP pattern on HRCT [3], not all patients are eligible or willing to undergo that procedure. As this study includes centers that are not necessarily ILD referral centers, there is the potential that these centers are not so experienced and comfortable to perform this invasive procedure. The subgroup analysis only looks at the diagnostic procedures done at baseline (i.e. until the first medical claim of IPF). In the majority of cases the surgical lung biopsy is only done after the result of the HRCT (in cases of possible or probable UIP) - which means the surgical lung biopsy would only be done after the baseline period and therefore not captured in the definition of the cohort/subgroup. Unlike clinical trials [5] that include a higher proportion of males, the gender distribution in this study is consistent with other publications on IPF populations, where approximately $50 \%$ of the patients were female [26, 27]. This may reflect women's greater likelihood to seek health-care services, therefore are more frequently observed in insurance claim databases [26].

Changes in the ICD-9 codes for IPF in October of 2011 did not influence the baseline characteristics of patients identified. However, if coding practice changes were implemented gradually, then some possible IPF patients with claims on or after October 2011 who were coded with the pre-October 2011 code (516.3) would have been excluded.

Comparisons to other publications should consider that study findings are influenced by the complexity of the IPF cohort definition, different distributions of age and sex, the coding used to define comorbidities, length of follow-up and the different underlying databases. Nevertheless, the reported prevalence and incidence rates observed in this study fell within the range of estimates reported in other publications. A systematic literature review [28] of the prevalence of pulmonary and extra pulmonary comorbidities among IPF patients included several of the outcomes included in this study and estimates ranged from 3-86\% for PH, 3-48\% for lung cancer, $6-91 \%$ for sleep apnea (various types), 6-67\% for COPD, 6-68\% for ischemic heart disease (IHD) and 0-94\% for GERD. Our reported prevalence estimates fell within these ranges, with baseline prevalence of $4.6 \%$ for $\mathrm{PH}, 16.1 \%$ for lung cancer, $8.1 \%$ for obstructive sleep apnea, $51.5 \%$ for COPD, $40.4 \%$ for IHD and $28.0 \%$ for GERD.

Of particular interest for IPF populations is the occurrence of exacerbations of IPF. The percent of patients in this cohort with ARWUC during follow-up was rather low with $2.4 \%$ (95\% CI: 2.0-2.8, data not shown). In comparison, a retrospective study of data collected from 461 patients with diagnosed IPF reported an annual percent of $14.2 \%$ of clinically defined acute respiratory worsening [29]. Reports in clinical trials have tended to be lower than this, and Raghu et al reported that ARW are believed to occur in between 5 and $10 \%$ of IPF patients per year [29]. The incidence of ARWUC is difficult to establish in claims data due to variations in methodologies used in different studies [29] and the numerous exclusionary comorbidities included in the definition, such as left heart failure, pulmonary embolism and other identifiable causes of lung injury. In addition, dyspnea, an essential component of the clinical definition of ARW may not be well-captured in claims data, leading to underestimation of the condition. This ARWUC algorithm is a proxy for clinically defined ARW and further validation is desirable. 
Table 4 Prevalence of comorbidities during the 12-month baseline period for the newly diagnosed IPF cohorts

\begin{tabular}{|c|c|c|c|c|c|c|}
\hline & \multicolumn{3}{|c|}{ IPF Cohort $(N=4,716)$} & \multicolumn{3}{|c|}{$\begin{array}{l}\text { IPF Diagnostic Testing Subgroup } \\
(N=2,518)\end{array}$} \\
\hline & $\begin{array}{l}\text { \# of Patients with } \\
\text { Condition During } \\
\text { Baseline }\end{array}$ & Prevalence (\%) & $95 \% \mathrm{Cl}$ & $\begin{array}{l}\text { \# of Patients with } \\
\text { Condition During } \\
\text { Baseline }\end{array}$ & Prevalence (\%) & $95 \% \mathrm{Cl}$ \\
\hline \multicolumn{7}{|l|}{ Primary } \\
\hline Acute Respiratory Worsening of Unknown Cause & 126 & 2.7 & $2.2-3.1$ & 126 & 5.0 & $4.2-5.9$ \\
\hline Pulmonary Hypertension & 219 & 4.6 & $4.0-5.2$ & 161 & 6.4 & $5.4-7.3$ \\
\hline Pulmonary Arterial Hypertension & 10 & 0.2 & $0.1-0.3$ & 5 & 0.2 & $0.0-0.4$ \\
\hline Lung Transplantation & 10 & 0.2 & $0.1-0.3$ & 2 & 0.1 & $0.0-0.2$ \\
\hline Lung Cancer & 757 & 16.1 & $15.0-17.1$ & 493 & 19.6 & $18.0-21.1$ \\
\hline Acute Myocardial Infarction ${ }^{a}$ & 125 & 2.7 & $2.2-3.1$ & 78 & 3.1 & $2.4-3.8$ \\
\hline Acute Myocardial Infarction ${ }^{b}$ & 128 & 2.7 & $2.3-3.2$ & 72 & 2.9 & $2.2-3.5$ \\
\hline \multicolumn{7}{|l|}{ Secondary } \\
\hline Gl Perforation & 11 & 0.2 & $0.1-0.4$ & 6 & 0.2 & $0.0-0.4$ \\
\hline Chronic Renal Failure/Insufficiency & 1,250 & 26.5 & $25.2-27.8$ & 718 & 28.5 & $26.8-30.3$ \\
\hline Hemorrhagic Diathesis or Coagulopathy & 120 & 2.5 & $2.1-3.0$ & 80 & 3.2 & $2.5-3.9$ \\
\hline Venous Thrombosis & 304 & 6.4 & $5.7-7.1$ & 190 & 7.5 & $6.5-8.6$ \\
\hline Pulmonary Embolism & 155 & 3.3 & $2.8-3.8$ & 98 & 3.9 & $3.1-4.6$ \\
\hline Stroke ${ }^{c}$ & 179 & 3.8 & $3.3-4.3$ & 91 & 3.6 & $2.9-4.3$ \\
\hline Stroke ${ }^{d}$ & 79 & 1.7 & $1.3-2.0$ & 39 & 1.5 & $1.1-2.0$ \\
\hline Cardiac Arrhythmia & 1,612 & 34.2 & $32.8-35.5$ & 935 & 37.1 & $35.2-39.0$ \\
\hline Congestive Heart Failure & 1,495 & 31.7 & $30.4-33.0$ & 849 & 33.7 & $31.9-35.6$ \\
\hline Ischemic Heart Disease & 1,906 & 40.4 & $39.0-41.8$ & 1,073 & 42.6 & $40.7-44.5$ \\
\hline Arterial Hypertension & 3,599 & 76.3 & $75.1-77.5$ & 1,941 & 77.1 & $75.4-78.7$ \\
\hline Neutropenia & 40 & 0.8 & $0.6-1.1$ & 32 & 1.3 & $0.8-1.7$ \\
\hline Pneumonia & 436 & 9.2 & $8.4-10.1$ & 286 & 11.4 & $10.1-12.6$ \\
\hline Sepsis & 245 & 5.2 & $4.6-5.8$ & 150 & 6.0 & $5.0-6.9$ \\
\hline COPD & 2,428 & 51.5 & $50.1-52.9$ & 1,387 & 55.1 & $53.1-57.0$ \\
\hline GERD & 1,321 & 28.0 & $26.7-29.3$ & 761 & 30.2 & $28.4-32.0$ \\
\hline Type 2 Diabetes Mellitus & 1,533 & 32.5 & $31.2-33.8$ & 846 & 33.6 & $31.8-35.4$ \\
\hline Obstructive Sleep Apnea & 383 & 8.1 & $7.3-8.9$ & 224 & 8.9 & $7.8-10.0$ \\
\hline Bronchitis & 1,911 & 40.5 & $39.1-41.9$ & 1,098 & 43.6 & $41.7-45.5$ \\
\hline Upper Respiratory Tract Infection & 451 & 9.6 & $8.7-10.4$ & 266 & 10.6 & $9.4-11.8$ \\
\hline Pulmonary Rehabilitation & 76 & 1.6 & $1.3-2.0$ & 52 & 2.1 & $1.5-2.6$ \\
\hline Acute Coronary Syndrome & 146 & 3.1 & $2.6-3.6$ & 82 & 3.3 & $2.6-3.9$ \\
\hline Angina Pectoris & 256 & 5.4 & $4.8-6.1$ & 153 & 6.1 & $5.1-7.0$ \\
\hline Bleeding & 567 & 12.0 & $11.1-13.0$ & 319 & 12.7 & $11.4-14.0$ \\
\hline Major Bleeding (Upper Gl) & 75 & 1.6 & $1.2-1.9$ & 40 & 1.6 & $1.1-2.1$ \\
\hline Major Bleeding (Lower Gl) & 312 & 6.6 & $5.9-7.3$ & 180 & 7.1 & $6.1-8.2$ \\
\hline Hemorrhage of the Rectum or Anus & 118 & 2.5 & $2.1-2.9$ & 69 & 2.7 & $2.1-3.4$ \\
\hline Blood in Stool & 127 & 2.7 & $2.2-3.2$ & 62 & 2.5 & $1.9-3.1$ \\
\hline Epistaxis & 120 & 2.5 & $2.1-3.0$ & 71 & 2.8 & $2.2-3.5$ \\
\hline Hemorrhoids & 106 & 2.2 & $1.8-2.7$ & 57 & 2.3 & $1.7-2.8$ \\
\hline Hemorrhoids with Bleeding & 30 & 0.6 & $0.4-0.9$ & 16 & 0.6 & $0.3-0.9$ \\
\hline Intracranial Hemorrhage & 39 & 0.8 & $0.6-1.1$ & 19 & 0.8 & $0.4-1.1$ \\
\hline
\end{tabular}


Table 4 Prevalence of comorbidities during the 12-month baseline period for the newly diagnosed IPF cohorts (Continued)

\begin{tabular}{|c|c|c|c|c|c|c|}
\hline & \multicolumn{3}{|c|}{ IPF Cohort $(N=4,716)$} & \multicolumn{3}{|c|}{$\begin{array}{l}\text { IPF Diagnostic Testing Subgroup } \\
(N=2,518)\end{array}$} \\
\hline & $\begin{array}{l}\text { \# of Patients with } \\
\text { Condition During } \\
\text { Baseline }\end{array}$ & Prevalence (\%) & $95 \% \mathrm{Cl}$ & $\begin{array}{l}\text { \# of Patients with } \\
\text { Condition During } \\
\text { Baseline }\end{array}$ & Prevalence (\%) & $95 \% \mathrm{Cl}$ \\
\hline Acute Pancreatitis & 47 & 1.0 & $0.7-1.3$ & 27 & 1.1 & $0.7-1.5$ \\
\hline Hepatic Failure & 14 & 0.3 & $0.1-0.5$ & 7 & 0.3 & $0.1-0.5$ \\
\hline Acute Renal Failure & 615 & 13.0 & $12.1-14.0$ & 378 & 15.0 & $13.6-16.4$ \\
\hline Depression (MDD only) & 575 & 12.2 & $11.3-13.1$ & 315 & 12.5 & $11.2-13.8$ \\
\hline Depression (MDD and other) & 648 & 13.7 & $12.8-14.7$ & 355 & 14.1 & $12.7-15.5$ \\
\hline
\end{tabular}

Optum Research Database - Medicare Advantage Population. Cohort Entry: 01 January 2008 - 30 September 2014

Abbreviations: IPF idiopathic pulmonary fibrosis, Cl confidence Interval, Gl gastrointestinal, COPD chronic obstructive pulmonary disease, GERD gastroesophageal reflux disease, $M D D$ major depressive disorder

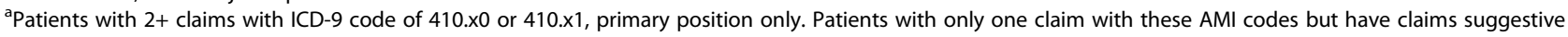
of death were classified as AMI cases. Claims must be within 7 days of each other and must be from the inpatient or emergency room setting

${ }^{b}$ Patients with an ICD-9-CM code for AMI $(410 . \times 0,410 . \times 1)$ in the principal (or primary) diagnosis position on at least one facility claim for hospitalization. Claims from emergency departments were not be included in the case identification as they are likely to lead to misclassification

ICD-9 code 430,431, 433.x1, or 434.x1, only in the primary or secondary diagnosis position. For patients identified by 430,431 , exclude if the following ICD-9

diagnosis codes are present on the same day: 800.xx-804.xx, 850.xx-854.xx (in any position); or V57.xx (in the primary position)

${ }^{d}$ ICD-9 code $430,431,433 . x 1$ or $434 . x 1$, restricted to the primary diagnosis position on at least 1 facility claim for hospitalization

Relative to findings reported in a similar study based on Optum's commercially insured population [30], the IPF cohort in this study population has substantially higher morbidity and mortality. This is likely due to the fact that the study population of this study was restricted to Medicare-eligible patients aged 65 years and above, while the previous study included IPF patients aged 40 years and older. Primary outcomes with notably higher IRs (per 1,000 pys) included AMI (34.4 vs 13.8), pulmonary hypertension ( 46.0 vs. 22.5$)$, lung cancer (26.0 vs. 17.6), and mortality (180.4 vs. 97.1$)$. The IR for lung transplantation was lower (1.0 vs. 6.0$)$, likely due to the practice in the US during this study period of restricting lung transplantation to patients under the age of 65 years [31]. IRs of most of the secondary outcomes were higher among the elderly population, in particular for chronic renal failure, congestive heart failure, pulmonary rehabilitation and intracranial hemorrhage, all of which were more than twice as high. In both studies, arterial hypertension was the secondary outcome with the highest IR and the most prevalent condition during baseline (76.3\% in elderly, (Table 5), 55.3\% in commercial (data not shown)). Although arterial hypertension is known to be highly prevalent in the US population, the high IR may also be due to the broad range of codes used to define this outcome [16, 17].

Collard et al [27] performed a similar analysis using US claims data from commercially insured and Medicare patients. The Collard et al [27] population was not restricted to the Medicare population $(20.8 \%$ were 64 years or younger) and many of the outcome definitions were less inclusive and consequently, IRs (per 1,000 pys) were consistently lower than those reported in the Optum population: heart failure (67.5 vs. 162.4), bronchitis (31.5 vs. 243.9$)$, AMI (21.7 vs. 34.4 ), diabetes (18.0 vs. 59.3 ), lung cancer (11.9 vs. 26.0), pulmonary embolism (10.7 vs. 25.0$)$, GERD (7.5 vs. 154.5$)$, pulmonary hypertension (6.8 vs. 46.0 ), depression (6.3 vs. 80.2 for MMD only) and sleep apnea (1.2 vs. 33.0).

Raimundo et al [32] also used insurance claims data to examine the impact of IPF on HCRU, separately in 2009, 2010 and 2011.The range of mean age of the cohorts was 69.8-71.3 and approximately 50\% of each cohort was male. In comparison, our study population had higher proportion of patients hospitalized in the past year $(51 \%$ vs. $37 \%)$, lower number of outpatient visits (14.8 vs. 18.5), lower use of oral corticosteroids (33.4\% vs. $44.6 \%)$.

This study has some key limitations. The study was done using automated medical and prescription claims. While claims data are extremely valuable for the efficient examination of health care outcomes and utilization, all claims databases have certain inherent limitations. Presence of a diagnosis code on a medical claim is not necessarily positive presence of disease, as it may be incorrectly coded or included as rule-out criteria rather than actual disease. Similarly, claims for diagnostic tests may be observed but results are not reported in claims data. We restricted the eligibility criteria to having a one-year look back for identification of incident cases of IPF, so patients who had an earlier diagnosis of IPF but not in the one-year lookback could have been misclassified as incident. However, this is unlikely as IPF is a chronic condition and it is highly likely that patients would be seeking health care during that one-year look back period. These limitations may lead to potential misclassification and impact this study due to the difficulty in diagnosing IPF when patients first present to medical 


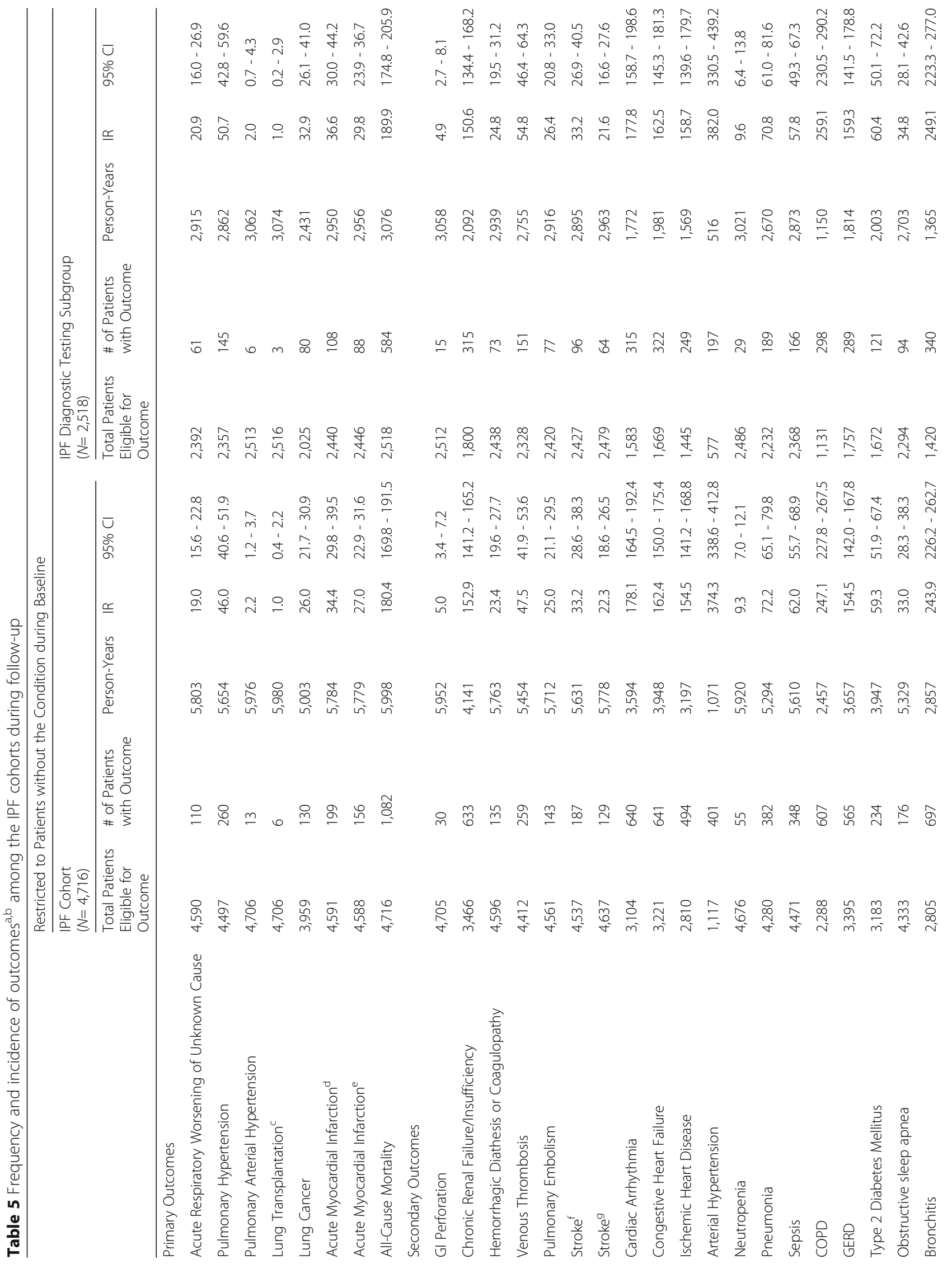




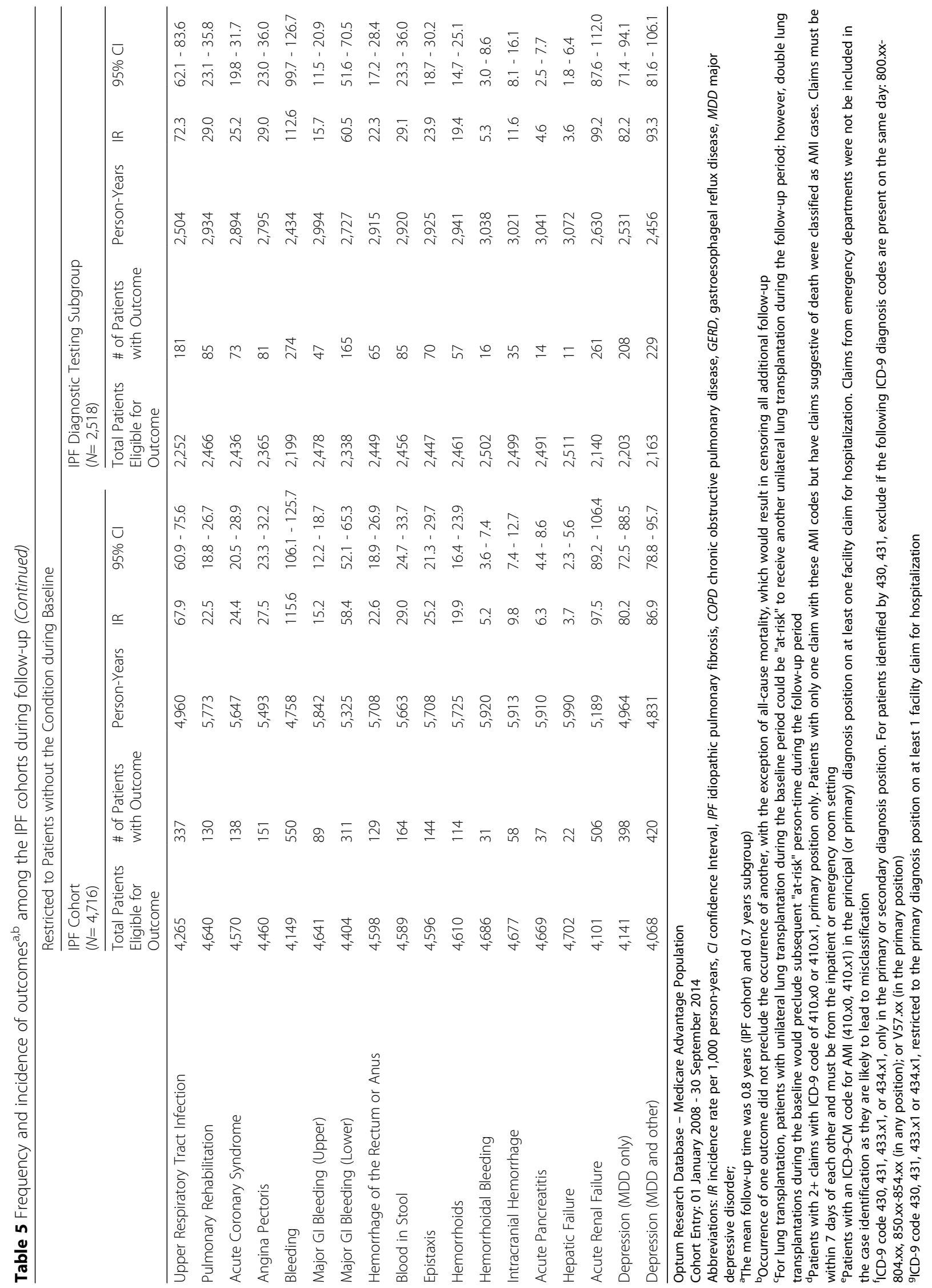


providers. Sensitivity and subgroup analyses were implemented to evaluate the impact that different selection criteria had on cohort characteristics, specifically creating a stricter cohort definition for the subgroup analysis which includes only those patients who had IPF diagnostic testing in line with the recommendations of the international diagnostic guidelines [3].

True incidence is difficult to identify, as it cannot be determined whether the code pertains to newly observed conditions or for care related to the conditions that were observed at an earlier (and possibly unobserved) date. Although this study focuses on the IR among patients without the condition observed in baseline, this may still result in the overestimation of rates of outcomes such as chronic and acute renal failure, which are captured by a broad range of non-specific codes, resulting in some of the highest incidence rates observed in this study. Some outcomes, such as epistaxis or other bleeding events may not require medical attention and therefore are not well captured in medical claims, leading to underestimation of those events. Medications that can be obtained without prescriptions (i.e., over-the-counter medications) are not observed in claims data. Medications that are given during an inpatient stay are also not captured, leading to underestimation of their use. In addition, given that there were no efficacious or approved treatments available during this study period other than lung transplantation, patients may have received additional (but unobserved in claims data) health care and medications through involvement in clinical trials.

Duration of follow-up can be limited in the Optum-MAPD database due to individuals changing into more traditional Medicare coverages or Medicare Advantage plans administered by other insurance companies. Thus, outcomes that occur after enrollment ends would not contribute to the prevalence or incidence rates. Although not systematically evaluated, there is a suggestion that as patients get sicker, they are more likely to disenroll from Medicare Advantage plans [33, 34].

Historically, the SSA DMF provided about $90 \%$ coverage for patients older than 65 years. Starting on 01 November 2011, the SSA determined that protected state records could no longer be disclosed. Section 205(r) of the Social Security Act prohibited the SSA from disclosing state death records received through their contracts with these states, except in limited circumstances. This has resulted in the reduction of available records on the public DMF by 1 million annually (about 30\% reduction) [35]. Some deaths may not be available in the DMF, and out-of-hospital deaths may be not be identified, potentially leading to underestimation of the mortality incidence rate.

There are several advantages to conducting this study in the Optum-MAPD. Unlike site-based or registry-based studies that are typically limited in population sample size, the Optum-MAPD contains millions of lives, allowing for broader investigations of drug use patterns and disease outcomes. This is especially valuable for investigating rare outcomes in a population with a rare disease such as IPF. Underlying information is geographically diverse across the US. Relative to the overall US Medicare population, the Optum MAPD population has a similar distribution of gender and age, members from the Northeast and Midwest, and proportion of members who are African-American, Hispanic or Asian. It has a higher proportion of members from the South and fewer from the West and a higher proportion with race categorized as other/unknown. The average length of enrollment in the MAPD is almost 5 years for this age group.

\section{Conclusions}

Elderly IPF patients experience a variety of comorbidities, both before and after diagnosis. This study helps to gain a better understanding of the outcomes of this disease, which is important to optimize management of this patient population and thus improve disease outcomes. The cohort characteristics were not affected by modifications to the cohort definition, suggesting that the definition of IPF captures similar patients despite variations in the operational definition of IPF. Therapies for IPF and for the associated comorbidities may reduce morbidity and associated HCRU of these patients.

\section{Additional file}

Additional file 1: ICD-9-CM Codes For Interstitial Lung Diseases Other Than Idiopathic Pulmonary Fibrosis (DOCX 18 kb)

\section{Abbreviations}

AMI: Acute myocardial infarction; ARW: Acute respiratory worsening; ARWUC: Acute respiratory worsening of unknown cause; Cl: Confidence interval; COPD: Chronic obstructive pulmonary disease; DMF: Death master file; EBV: Epstein-Barr virus; FDA: Food and Drug Administration;

GERD: Gastroesophageal reflux disease; Gl: Gastrointestinal; HCRU: Health care utilization; HRCT: High-resolution computed tomography; IHD: Ischemic heart disease; ILD: Interstitial lung disease; IPF: Idiopathic pulmonary fibrosis; IQR: Interquartile range; IR: Incidence rate; MAPD: Medicare Advantage and Part D plan; MDD: Major depressive disorder; NAC: N-acetyl cysteine; $\mathrm{PAH}$ : Pulmonary arterial hypertension; $\mathrm{PH}$ : Pulmonary hypertension; pys: Person-years; SD: Standard deviation; SLB: Surgical lung biopsy; SSA: Social Security Administration; UIP: Interstitial pneumonia; US: United States

\section{Acknowledgements}

The authors would like to acknowledge Synne Wing for her project oversight and Danielle Cupka for her technical assistance in preparing the manuscript.

\section{Funding}

This study was funded by a research contract with Boehringer Ingelheim International $\mathrm{GmbH}$, which granted Optum oversight of the study conduct, reporting, and interpretation, as well as final wording of any resulting manuscripts. Employees of the funding institution were involved in the 
design, analysis and interpretation of the data, and in the writing of the manuscript, and are co-authors of the manuscript.

\section{Availability of data and materials}

The datasets generated and analyzed during the current study are not publicly available due to the restrictions of the data license, but may be available from Optum through a data license agreement by interested parties.

\section{Authors' contributions}

$\mathrm{KM}, \mathrm{CE}, \mathrm{NH}$, LW contributed to the study concept and design. CC and HN acquired the data. KM drafted the manuscript. CE, NH, LW critically revised the manuscript for important intellectual content. All authors contributed to the analysis and interpretation of data. All authors read and approved the final manuscript.

\section{Ethics approval and consent to participate}

This study was approved by the Western Institutional Review Board (WIRB, Study No.: 1178316). This Board found that this research met the requirements for a waiver of consent under 45 CFR 46.116(d), thus no further permissions were required to utilize the datasets for this study.

\section{Consent for publication}

Not applicable.

\section{Competing interests}

$\mathrm{NH}$ and LW are employees for Boehringer Ingelheim., CE and HN are employees of Optum. KM and CC were employees of Optum at the time this study was conducted. The authors have no conflicts of interest to report.

\section{Publisher's Note}

Springer Nature remains neutral with regard to jurisdictional claims in published maps and institutional affiliations.

\section{Author details}

'Optum Epidemiology, Boston, MA, USA. ${ }^{2}$ Boehringer Ingelheim International $\mathrm{GmbH}$, Ingelheim, Germany. ${ }^{3}$ Boehringer Ingelheim Pharmaceuticals International, Ridgefield, CT, USA. ${ }^{4}$ Optum Epidemiology, 315 E. Eisenhower Parkway, Suite 305, Ann Arbor, Ml 48108, USA.

\section{Received: 6 July 2018 Accepted: 4 December 2018}

\section{Published online: 10 January 2019}

\section{References}

1. Fernández Pérez ER, Daniels CE, Schroeder DR, St Sauver J, Hartman TE, Bartholmai BJ, Yi ES, Ryu JH. Incidence, prevalence, and clinical course of idiopathic pulmonary fibrosis. A population-based study. Chest. 2010;137(1): 129-37.

2. Ley B, Collard HR, King TE Jr. Clinical course and prediction of survival in idiopathic pulmonary fibrosis. Am J Respir Crit Care Med. 2011;183(4):431-40.

3. Raghu G, Collard HR, Egan JJ, Martinez FJ, Behr J, Brown KK, Colby TV, Cordier JF, Flaherty KR, Lasky JA, Lynch DA, Ryu JH, Swigris JJ, Wells AU, Ancochea J, Bouros D, Carvalho C, Costabel U, Ebina M, Hansell DM, Johkoh T, Kim DS, King TE, Kondoh Y, Myers J, Müller NL, Nicholson AG, Richeldi L, Selman M, Dudden RF, Griss BS, Protzko SL, Schünemann HJ, ATS/ERS/JRS/ ALAT Committee on Idiopathic Pulmonary Fibrosis. An official ATS/ERS/JRS/ ALAT statement: idiopathic pulmonary fibrosis: evidence-based guidelines for diagnosis and management. Am J Respir Crit Care Med. 2011;183(6):788-824.

4. Fraser E, Hoyles RK. Therapeutic advances in idiopathic pulmonary fibrosis. Clin Med. 2016;16(1):42-51.

5. Richeldi L, Cottin V, du Bois RM, Selman M, Kimura T, Bailes Z, SchlenkerHerceg R, Stowasser S, Brown KK. Nintedanib in patients with idiopathic pulmonary fibrosis: combined evidence from the TOMORROW and INPULSIS ${ }^{\oplus}$ ) trials. Respir Med. 2016;113:74-9.

6. Collard HR, Moore BB, Flaherty KR, Brown KK, Kaner RJ, King TE Jr, Lasky JA, Loyd JE, Noth I, Olman MA, Raghu G, Roman J, Ryu JH, Zisman DA, Hunninghake GW, Colby TV, Egan JJ, Hansell DM, Johkoh T, Kaminski N, Kim DS, Kondoh Y, Lynch DA, Müller-Quernheim J, Myers JL, Nicholson AG, Selman M, Toews GB, Wells AU, Martinez FJ, Idiopathic Pulmonary Fibrosis Clinical Research Network Investigators. Acute exacerbations of idiopathic pulmonary fibrosis. Am J Respir Crit Care Med. 2007;176(7):636-643.
7. Kirson NY, Birnbaum HG, Ivanova Jl, Waldman T, Joish V, Williamson T. Prevalence of pulmonary arterial hypertension and chronic thromboembolic pulmonary hypertension in the United States. Curr Med Res Opin. 2011;27(9):1763-8.

8. Cooper GS, Yuan Z, Stange KC, Dennis LK, Amini SB, Rimm AA. The sensitivity of Medicare claims data for case ascertainment of six common cancers. Med Care. 1999;37(5):436-44.

9. McBean AM, Babish JD, Warren JL. Determination of lung cancer incidence in the elderly using Medicare claims data. Am J Epidemiol. 1993;137(2):226-34.

10. Curtis JR, Chen SY, Werther W, John A, Johnson DA. Validation of ICD-9-CM codes to identify gastrointestinal perforation events in administrative claims data among hospitalized rheumatoid arthritis patients. Pharmacoepidemiol Drug Saf. 2011;20(11):1150-8.

11. Foley RN, Murray AM, Li S, Herzog CA, McBean AM, Eggers PW, Collins AJ. Chronic Kidney Disease and the Risk for Cardiovascular Disease, Renal Replacement, and Death in the United States Medicare Population, 1998 to 1999. J Am Soc Nephrol. 2005;16(2):489-95.

12. Winkelmayer WC, Schneeweiss S, Mogun H, Patrick AR, Avorn J, Solomon $\mathrm{DH}$. Identification of individuals with CKD from Medicare claims data: a validation study. Am J Kidney Dis. 2005;46(2):225-32.

13. Tamariz L, Harkins T, Nair V. A systematic review of validated methods for identifying venous thromboembolism using administrative and claims data. Pharmacoepidemiol Drug Saf. 2012;21:154-62.

14. Saczynski JS, Andrade SE, Harrold LR, Tjia J, Cutrona SL, Dodd KS, Goldberg RJ, Gurwitz JH. A systematic review of validated methods for identifying heart failure using administrative data. Pharmacoepidemiol Drug Saf. 2012; 21:129-40.

15. DiMartino LD, Hammill BG, Curtis LH, Gottdiener JS, Manolio TA, Powe NR, Schulman KA. External validity of the cardiovascular health study: a comparison with the Medicare population. Med Care. 2009;47(8):916-23.

16. Johnson ML, Petersen LA, Sundaravaradan R, Byrne MM, Hasche JC, Osemene NI, Wei II, Morgan RO. The association of Medicare drug coverage with use of evidence-based medications in the Veterans Health Administration. Ann Pharmacother. 2009;43(10):1565-75.

17. Quan H, Khan N, Hemmelgarn BR, Tu K, Chen G, Campbell N, Hill MD, Ghali WA, FA MA. Hypertension Outcome and Surveillance Team of the Canadian Hypertension Education Programs. Validation of a case definition to define hypertension using administrative data. Hypertension. 2009;54(6):1423-8.

18. Dutro MP, Gerthoffer TD, Peterson ED, Tang SS, Goldberg GA. Treatment of hypertension and dyslipidemia or their combination among US managedcare patients. J Clin Hypertens. 2007;9:684-91.

19. Kim SY, Solomon DH, Liu J, Chang CL, Daniel GW, Schneeweiss S. Accuracy of identifying neutropenia diagnoses in outpatient claims data. Pharmacoepidemiol Drug Saf. 2011;20(7):709-13.

20. Cascini S, Agabiti N, Incalzi RA, Pinnarelli L, Mayer F, Arcà M, Fusco D, Davoli M. Pneumonia burden in elderly patients: a classification algorithm using administrative data. BMC Infect Dis. 2013;13:559.

21. Carnahan RM, Herman RA, Moores KG. A systematic review of validated methods for identifying transfusion-related sepsis using administrative and claims data. Pharmacoepidemiol Drug Saf. 2012;21:222-9.

22. Blanchette CM, DeKoven M, De AP, Roberts M. Probabilistic data linkage: a case study of comparative effectiveness in COPD. Drugs Context. 2013;2013: 212258

23. Gosselin A, Luo R, Lohoues H, Toy E, Lewis B, Crawley J, Duh MS. The impact of proton pump inhibitor compliance on health-care resource utilization and costs in patients with gastroesophageal reflux disease. Value Health. 2009;12(1):34-9.

24. Halpern R, Kothari S, Fuldeore M, Zarotsky V, Porter V, Dabbous O, Goldstein $J$. GERD-related health care utilization, therapy, and reasons for transfer of GERD patients between primary care providers and gastroenterologists in a US managed care setting. Dig Dis Sci. 2010;55(2):328-37.

25. Hebert PL, Geiss LS, Tierney EF, Engelgau MM, Yawn BP, McBean AM. Identifying persons with diabetes using Medicare claims data. Am J Med Qual. 1999;14(6):270-7.

26. Yu YF, Wu N, Chuang CC, Wang R, Pan X, Benjamin NN, Devercelli G, Coultas DB. Patterns and economic burden of hospitalizations and exacerbations among patients diagnosed with idiopathic pulmonary fibrosis. J Manag Care Spec Pharm. 2016;22(4):414-23.

27. Collard HR, Ward AJ, Lanes S, Cortney Hayflinger D, Rosenberg DM, Hunsche E. Burden of illness in idiopathic pulmonary fibrosis. J Med Econ. 2012;15(5):829-35

28. Thompson AE, Anisimowicz Y, Miedema B, Hogg W, Wodchis WP, AubreyBassler K. The influence of gender and other patient characteristics on 
health care-seeking behaviour: a QUALICOPC study. BMC Fam Practice. 2016;17:38.

29. Raghu G, Amatto VC, Behr J, Stowasser S. Comorbidities in idiopathic pulmonary fibrosis patients: a systematic literature review. Eur Respir J. 2015: 46(4):1113-30

30. Kim DS. Acute exacerbations in patients with idiopathic pulmonary fibrosis. Respir Res. 2013;14:86.

31. Mortimer K, Bartels D, Capapey J, Yang J, Gately R, Enger C. Characterizing idiopathic pulmonary fibrosis patients using US health plan claims data. Submitted for publication.

32. Biswas Roy S, Alarcon D, Walia R, Chapple KM, Bremner RM, Smith MA. Is there an age limit to lung transplantation? Ann Thorac Surg. 2015;100(2): 443-51.

33. Raimundo K, Chang E, Broder MS, Alexander K, Zazzali J, Swigris JJ. Clinical and economic burden of idiopathic pulmonary fibrosis: a retrospective cohort study. BMC Pulm Med. 2016;16:2.

34. Schulte F. As seniors get sicker, they're more likely to drop Medicare advantage plans. https://www.npr.org/sections/health-shots/2017/07/05/ 535381473/as-seniors-get-sicker-theyre-more-likely-to-drop-medicareadvantage-plan. Accessed 10 Nov 2017.

35. NTIS Important Notice. https://classic.ntis.gov/assets/pdf/import-changedmf.pdf. Accessed 19 Dec 2018

Ready to submit your research? Choose BMC and benefit from:

- fast, convenient online submission

- thorough peer review by experienced researchers in your field

- rapid publication on acceptance

- support for research data, including large and complex data types

- gold Open Access which fosters wider collaboration and increased citations

- maximum visibility for your research: over $100 \mathrm{M}$ website views per year

At $\mathrm{BMC}$, research is always in progress.

Learn more biomedcentral.com/submissions 